\title{
Experiencing climate change: revisiting the role of local weather in affecting climate change awareness and related policy preferences
}

\author{
Lea Gärtner ${ }^{1}$ (D) Harald Schoen ${ }^{1}$ (D) \\ Received: 30 March 2021 / Accepted: 14 July 2021/ Published online: 6 August 2021 \\ (C) The Author(s) 2021
}

\begin{abstract}
Over the last few years, climate change has risen to the top of the agenda in many Western democracies, backed by a growing share of voters supporting climate protection policies. To understand how and why these changes came about, we revisit the question whether personal experiences with increasingly unusual local weather conditions affect people's beliefs about climate change and their related attitudes. We first take a closer look at the theoretical underpinnings and extend the theoretical argument to account for the differential impact of different weather phenomena, as well as the role of prior beliefs and individual reference frames. Applying mixed-effects regressions to a novel dataset combining individual-level multi-wave panel survey data from up to 18,010 German voters collected from 2016 to 2019 with weather data from 514 weather stations, we show that personally experiencing unusual or extreme local weather did not shape people's awareness of climate change as a political problem or their climate policy preferences in a sustained manner. Even among people who may be considered most likely to exhibit such effects, we did not detect them. Moreover, we demonstrate that the common modeling strategy of combining fixed-effects regression with clustered standard errors leads to severely reduced standard errors and substantively different results. We conclude that it cannot be taken for granted that personally experiencing extreme weather phenomena makes a difference in perceptions of climate change and related policy preferences.
\end{abstract}

Keywords Climate change Policy preferences - Experiential learning $\cdot$ Mixed-effects regression · Panel data

Lea Gärtner

lea.gaertner@uni-mannheim.de

Harald Schoen

harald.schoen@uni-mannheim.de

1 Chair for Political Science, Political Psychology, University of Mannheim, A5, 6, 68131 Mannheim, Germany 


\section{Introduction}

Over the last few years, climate change has risen to the top of the agenda in many Western democracies. From the European Green Deal to President Biden's Clean Energy Revolution for the USA, longstanding commitments to fight climate change are tentatively being put into action, in accordance with a growing share of the electorate supporting such action (e.g., Eurobarometer 2019; Poortinga et al. 2018; Flynn et al. 2021). People's increasing awareness of climate change as a problem and their changing preferences for related policies raise the question how and why these changes came about. A burgeoning literature linking climate change attitudes to personally experienced weather events suggests that an increase in unusual weather conditions such as heatwaves, droughts, severe storms, and floods in recent years may have made climate change more tangible, as people now experience its consequences firsthand (e.g., Egan and Mullin 2012; Krosnick et al. 2006; Li et al. 2011; Myers et al. 2013). Drawing on theories of risk perception, it is argued that personal experience, more than even large amounts of cognitive information, offers an easily available cue attesting to the immediacy of the risk and, hence, the personal relevance of an issue (e.g., Howe et al. 2014). The empirical evidence largely supports this linkage, although the effects of objectively measured weather conditions tend to be small and ephemeral compared to other predictors of climate change beliefs and attitudes, including the effects of self-reported experiences with unusual or extreme weather (cf. Hornsey et al. 2016; Marquart-Pyatt et al. 2014; McCright and Dunlap 2011). These findings could reflect the methodological challenges involved in matching weather and survey data but may also point to more fundamental theoretical issues. In the former case, research designs using more fine-grained data may reveal more substantial effects. In the latter case, there may be sound theoretical reasons not to expect large or lasting effects of personal experiences on climate change attitudes.

We revisit the question whether personally experienced variations in local weather conditions alter people's beliefs about climate change and their related attitudes, taking a closer look at the theoretical underpinnings and drawing on a new dataset that allows us to address some of the challenges associated with objective weather data. The theoretical argument that links personal experience to an increased sense of risk that may result in an according change in individual beliefs and attitudes is sound and empirically supported. However, in the case of climate change, this argument needs to be elaborated to account for the differential impact of different weather phenomena, as well as the role of prior beliefs and individual reference frames in shaping this impact. Furthermore, given the range of available climate policy options, the link between personal experience and attitudes is based on additional assumptions that need to be specified. We hence extend the theoretical argument to account for the specific features of the case.

To test whether and how objective variations in local weather conditions affect people's awareness of climate change as a problem and their related attitudes, we combine individuallevel panel data from up to 18,010 respondents with objective weather data from 514 weather stations currently in use across Germany, which was first strongly affected by climate change in 2018 (Rueter 2019). The panel structure of the data enables us to trace intra-individual changes in the salience of climate change and related policy preferences over time while minimizing unobserved heterogeneity, thus facilitating causal inference (Howe et al. 2019; Palm et al. 2017; Shao et al. 2014). The high geospatial resolution of the weather data allows us to match individual attitudes and weather conditions at the station level, maximizing the likelihood that people actually experienced the weather attributed to their area and thereby 
eliminating a great number of confounding factors (cf. Konisky et al. 2016). Both strategies have been employed in previous research to overcome challenges to causal inferences, but to date, only one other study has combined these strengths in the same research design (Ripberger et al. 2017).

\section{Theory}

When looking for factors that shape people's beliefs about climate change and attitudes towards related policies, local weather appears to be a natural candidate. People experience local weather directly, suggesting that this information may be salient in forming climate change beliefs and related policy attitudes. In line with this personal experience model, numerous studies have found a small but largely consistent influence of unusual variations in local weather on climate change beliefs, levels of concern, and attitudes towards related policies. Real and perceived deviations from long-term average temperatures (Akerlof et al. 2013; Brooks et al. 2014; Capstick and Pidgeon 2014; Egan and Mullin 2012; Li et al. 2011; Myers et al. 2013), as well as extreme weather events such as severe droughts, storms, and flooding (Borick and Rabe 2014; Krosnick et al. 2006; Lujala et al. 2015; Reser et al. 2012; Spence et al. 2011; Taylor et al. 2014; van der Linden 2015; but see Brulle et al. 2012), have all been linked to an increased belief in and concern about climate change. Individuals who have experienced extreme weather events have also been shown to become more supportive of climate protection policies (Rudman et al. 2013). The extensive literature on risk perceptions suggests that personal experience serves as an easily available cue for people's risk assessments, making abstract risks such as climate change more tangible (Kahneman et al. 1982; Keller et al. 2006; Kuchler and Zafar 2019; Reser et al. 2014; Weber 2006). People generally tend to underestimate risks, yet they routinely overestimate risks they have previously experienced, and this increased sense of personal risk motivates behavioral changes (Fazio and Zanna 1981; Howe et al. 2014, p. 382; for a comprehensive discussion see Whitmarsh 2008). Hence, unusual variations in local weather may serve as a simple cue attesting to the personal relevance of climate change.

However, a closer look at this link reveals that the theoretical connection between people's personal experiences with local weather conditions and their beliefs about climate change and attitudes towards related policies may not be as straightforward as it seems. It requires people to respond to certain local weather phenomena by changing their beliefs and attitudes in a specific direction, building on assumptions that deserve closer attention. To begin with, citizens' political perceptions and attitudes are often affected by pre-existing views and predispositions leading to biased information processing (e.g., Kunda 1990; Lodge and Taber 2013; Lord et al. 1979). For example, partisan attachments have been demonstrated to shape people's perceptions and make them less responsive to real-world events than one may expect (e.g., Devine-Wright et al. 2015; Evans and Pickup 2010; Fielding and Hornsey 2016; Hoffarth and Hodson 2016; but see Ziegler 2017). Long-standing political preferences may thus attenuate the responsiveness of citizens' attitudes towards climate change and related policies to local weather phenomena. In a similar vein, existing beliefs about climate change likely affect the probability that local weather conditions are perceived as indicative of global climate trends. For climate change skeptics, defensive motivated reasoning can be expected to prevent attitudinal changes in response to local weather phenomena (e.g., Kunda 1990; Lodge and Taber 2013; Lord et al. 1979). Put differently, it is an open question whether even extreme 
local weather phenomena are sufficiently significant for many people to overcome the impact of their predispositions. ${ }^{1}$ As a consequence, unusual local weather conditions may not significantly influence people's climate change concern or their related attitudes (H1).

Even if local weather conditions did affect people's climate change beliefs and attitudes, this influence cannot be expected to be universal. Looking at the dependent variables that have been considered in prior research, they appear to differ in their substantive closeness to local weather conditions. Building on the far-ranging scientific consensus (Field et al. 2012), extreme local weather conditions are linked to changes in the global climate and may thus be considered indicative of climate change. Accordingly, extreme local weather conditions likely affect people's beliefs about the existence of climate change and its perceived personal importance. It is quite a different matter, however, to link such experiences to support for specific policies. In the case under study, people may agree on the existence of climate change and even perceive it as an important problem, yet still disagree about the best way to address it. Depending on their beliefs and values, some people will plead for climate protection, whereas others prefer adaptation (Tvinnereim et al. 2017; also see Alló and Loureiro 2014; Schwirplies 2018). From this follows the expectation that attitudes towards climate-related policies are less likely to exhibit systematic effects of local weather conditions than beliefs about the existence of climate change and its personal importance $(\mathrm{H} 2)$.

Moreover, weather is a multidimensional concept that includes a variety of phenomena such as temperature, pressure, and precipitation. Given that climate change is most often referred to in terms of rising temperatures (consider the term "global warming") or in the context of extreme weather events such as hurricanes and floods, certain weather phenomena such as heat and drought may be easier to link to climate change than others such as unusually intense snow fall and cold, because their connection to a trend characterized primarily by higher average temperatures is less obvious (van der Linden 2014; Weber 2010; also see Lang 2014). Thus, local weather conditions related to rising temperatures and weather extremes are expected to be more likely to influence people's climate change concern and their support for climate protection policies than other weather events (H3).

The global nature of climate change also raises the question whether unusual variations in local weather will be considered informative given that most local weather conditions, however unusual for the moderate Western European climate, will seem negligible compared to the global consequences of climate change, which tend to receive extensive media attention. As a result, we expect that local weather conditions are more likely to influence people who have a strong focus on local conditions ( $\mathrm{H} 4 \mathrm{a}$ ), motivated by, for example, genuine parochialism (e.g., Inglehart 1970) or self-interest. In other words, some people may primarily care for their local surroundings, whereas others may not generally ignore developments beyond their local region but could be particularly responsive to local weather conditions because of their self-interest. Consider, for instance, farmers and elderly people, who have a strong interest in local weather conditions and may thus be particularly responsive to them (Filiberto et al. 2009). However, as argued above, strong attachment to the local community may prevent people from linking local conditions to global trends, leading us to expect that people who have a strong focus on local conditions are less likely to exhibit changes in their beliefs about the existence of climate change (H4b).

\footnotetext{
${ }^{1}$ In addition, we do not know how quickly people's expectations adapt to recent experiences. At the extreme, expectations may change quickly, making even extreme weather events seem ordinary and thus no longer noteworthy.
} 
With regard to policy attitudes, the considerations about predispositions presented above suggest that local weather conditions may primarily influence people who already accept the existence of climate change, yet do not endorse a certain set of policies. For those fully aware of the serious global ramifications of climate change, even extreme local weather conditions will probably not be alarming enough to influence their positions on climate policy. However, for people who accept the existence of climate change but do not perceive its consequences as a personal risk, unusual variations in local weather may make climate protection seem more urgent and thus prompt changes in their political attitudes. Such changes may follow from an improved understanding of the linkages between local weather variations and global climate change, or from a simple attribution error enabling people to link (perceived) local weather extremes to support for local policy measures while disregarding the complexity of this global phenomenon (Gilbert and Malone 1995; Jones and Harris 1967; Lord et al. 1979; Ross 1977). Despite their larger substantive distance to local weather phenomena, we thus hypothesize that policy-related attitudes are more likely to respond to these conditions for people who already accept the existence of climate change (H5).

Taken together, the analysis suggests that effects of local weather conditions on beliefs about the existence of climate change, the awareness of climate change as a problem, and support for climate protection policies cannot be taken for granted. If anything, local weather conditions commonly associated with climate change should influence the problem awareness and, less so, the climate policy preferences of people with a strong interest in local weather conditions who already accept the existence of climate change.

\section{Case}

To understand the impact of personally experienced weather events, we study changes in Germans' awareness of climate change as a problem and their climate policy preferences between 2016 and 2019. Though not the most intuitive choice at the first glance, this case offers two distinct advantages in testing the independent effect of local weather conditions. First, although an overwhelming majority of Germans accept the existence of climate change (ESS Round 8 2016), assessments of the risks associated with climate change and positions on climate protection policies vary widely (Roßteutscher et al. 2018). Moving beyond the often studied influence of weather events on beliefs about the existence of climate change allows us to capture subtler variations in people's awareness of climate change as a problem and their corresponding attitudes, which are more closely related to decisions about concrete policies than broader beliefs about the existence of climate change.

Second, although Germany has a relatively uniform cold-temperate climate (Peel et al. 2007), the past years have seen an ever increasing number of weather extremes (Rueter 2019). Importantly, the impact of these events was not evenly distributed across the country but affected some regions, counties, and sometimes even cities more than others. Temperatures climbed to record highs in 2018 and 2019, causing or exacerbating droughts across the country (Friedrich and Kaspar 2019; Imbery et al. 2019; Meinert et al. 2019). With forest fires requiring evacuation in some parts and water rationing in others, a phenomenon that mainly concerned farmers for a long time suddenly affected people's everyday lives (Handelsblatt 2019; Nicolai 2018; Zeit Online 2018). At the same time, storms were frequent and unusually destructive, interrupting travel routes and resulting in considerable property damages (Deutsche Welle 2018; Rueter 2019). In some areas, local flooding and heavy snowfalls put 


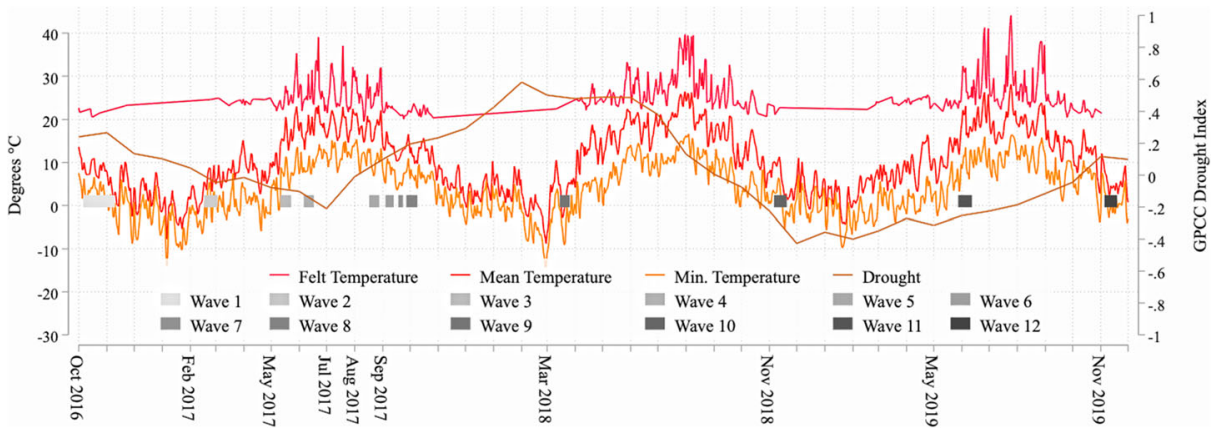

Fig. 1 Timeline of GLES Campaign Panel survey waves and average heat-related weather conditions. GLES Campaign Panel survey waves were collected from 10/06-11/10/2016 (wave 1), 02/16-03/03/2017 (wave 2), 05/ 11-05/23/2017 (wave 3), 07/06-07/17/2017 (wave 4), 08/17-08/28/2017 (wave 5), 09/04-09/13/2017 (wave 6), 09/18-09/23/2017 (wave 7), 09/27-10/09/2017 (wave 8), 03/15-03/26/2018 (wave 9), 11/06-11/20/2018 (wave 10), 05/28-06/12/2019 (wave 11), and 11/05-11/19/2019 (wave 12); depicted are daily temperatures and monthly GPCC-DI scores (Source: DWD) averaged across respondents

people out of their homes (DWD 2018; WAZ 2019). While many of these events were closely followed by the media and may thus have influenced attitudes towards climate change on the aggregate level, their impact was only personally experienced in relatively small areas. Hence, the studied case is well suited to examine the independent impact of personally experienced weather conditions on climate change perceptions and related attitudes.

\section{Data and methods}

To explore the impact of objective local weather on people's climate change attitudes, we combine panel survey data from the 2017 Campaign Panel of the German Longitudinal Election Study (Roßteutscher et al. 2018) with objective weather data provided by the German Meteorological Service (DWD Climate Data Center (CDC) 2018; Ziese et al. 2013) and the European Centre for Medium-Range Weather Forecasts (ECMWF). This allows us to match the climate change attitudes of up to 18,010 respondents to objective weather data from 514 weather stations currently in use across Germany. By combining the most fine-grained geospatial resolution to date with the possibility to trace intra-individual changes in the policy preferences of respondents who experienced different weather conditions over time, the used data offer an advantage over most prior studies that utilize these strengths in isolation (for an exception, see Ripberger et al. 2017). Figure 1 depicts the collection dates of the twelve waves of the GLES Campaign Panel that were used in the analyses against the backdrop of aggregated levels of temperatures and drought over the same period (additional indicators are included in Appendix 1). The GLES Campaign Panel 2017 draws its respondents from an online access panel. Although quotas are used to ensure that the sample is representative with regard to respondents' gender, age, and education levels, self-selection and panel attrition introduce biases not found in random probability samples. For instance, respondents tend to be slightly more involved in politics and more partisan than the larger population. ${ }^{2}$ However,

\footnotetext{
${ }^{2}$ On a scale from 0 to 1 , respondents' political interest averages at 0.59 in the Campaign Panel, compared to 0.56 in the Cumulated Pre- and Post-election Cross Section (GLES 2019), which uses a random probability sample. Similarly, the share of party identifiers is $77.9 \%$ in the Campaign Panel, compared to $76.3 \%$ in the cross section.
} 
because we are interested in intra-individual changes rather than absolute levels, these biases would threaten the validity of our results only if the affected variables moderated the influence of local weather conditions on respondents' climate change concern and related attitudes. Since more politically involved respondents may have more stable attitudes, we compared the effects for politically less involved respondents to the effects observed in the full sample (see Appendix 2), but the results remain substantively unchanged.

To measure unusual variations in local weather, we constructed daily binary indicators of absolute and relative heat, oppressiveness, absolute and relative cold, (thunder-)storms, heavy rain- and snowfall, and drought. ${ }^{3}$ We relied on the DWD's extreme weather classification scheme to identify weather conditions that would prompt extreme weather alerts and should therefore be unusual enough to capture respondents' attention (see Appendix 4 for detailed coding information). Although studies relying on self-reported exposure to extreme or unusual weather routinely find larger effects than studies based on objective weather conditions (Akerlof et al. 2013; Brooks et al. 2014; Hornsey et al. 2016; Taylor et al. 2014), these studies are not well-suited for causal inference because item priming effects cannot be precluded and perceptions of objective weather conditions are affected by existing climate change beliefs (Howe and Leiserowitz 2013; Myers et al. 2013). Moreover, the perception of unusual or extreme weather is an important step in the causal chain between objective weather conditions and climate change attitudes, which is omitted in these studies, increasing the risk for overestimating effects. To avoid the challenges associated with self-reports and to maximize the likelihood that respondents actually experienced objective weather conditions recorded for their area, we matched the postal codes of up to 18,010 respondents who participated in one or more waves of the 2017 GLES Campaign Panel (Roßteutscher et al. 2018) to one of 514 German weather stations operated by the DWD. To this end, we minimized the Euclidian distance between the coordinates marking the center of a postal area and the coordinates of the weather stations. We added indices for thunderstorms (Hersbach et al. 2018) and droughts (Ziese et al. 2014) available at different grid resolutions following the same procedure.

These regional clusters are extremely small compared to the commonly used Climate Extremes Index (CEI), which measures weather extremes for nine interstate regions across the USA (e.g., Konisky et al. 2016; Marquart-Pyatt et al. 2014). With a mean distance of 0.1 degrees in latitude/longitude (approximately 7 to $11 \mathrm{~km}$ ) compared to 0.43 degrees in latitude/ longitude (approximately 40 to $48 \mathrm{~km}$ ), the distances between weather stations and postal areas are also considerably smaller than the distances resulting from matching US weather stations and Zip Code Tabulation Areas (ZCTA; Egan and Mullin 2012). ${ }^{4}$ Figure 2 shows the distribution of weather stations (green markers) and postal areas using the example of ten weather stations located in urban centers (first and third column) and rural areas (second and fourth column) across Germany. The gridlines indicate degree minutes, roughly $1.2 \mathrm{~km}$ in latitude and $1.9 \mathrm{~km}$ in longitude, illustrating the different shapes and sizes the areas associated with the weather stations can take. As weather data is available only at the station level, the same value is recorded for all postal codes linked to the station. The background coloring in Fig. 2 indicates the mean daily temperature on June 6, 2018, which averaged $19.5^{\circ} \mathrm{C}$ and was thus $4.1{ }^{\circ} \mathrm{C}$ higher than the long-time normal temperature. Importantly, the mean temperature

\footnotetext{
${ }^{3}$ Given the rarity of very extreme weather events, continuous measures of weather extremity do not offer enough variation to obtain reliable estimates, but robustness checks with two survey waves show no substantial differences in the results in cases where the models converge (see Appendix 3).

${ }^{4}$ Even the maximum distance of 0.39 degrees in latitude/longitude (approximately 28 to $43 \mathrm{~km}$ ) is still smaller than the mean distance between US weather stations and ZCTAs.
} 

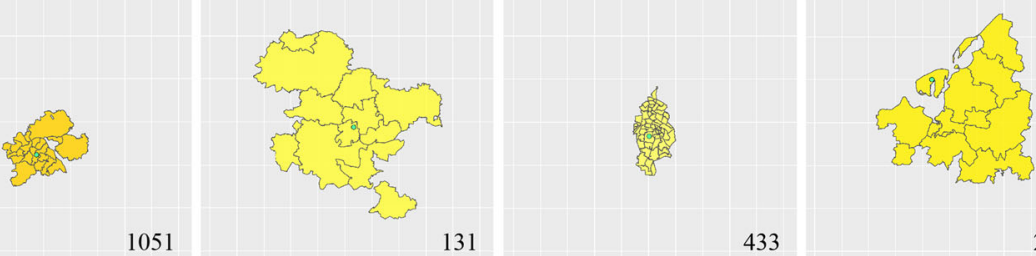

131

433
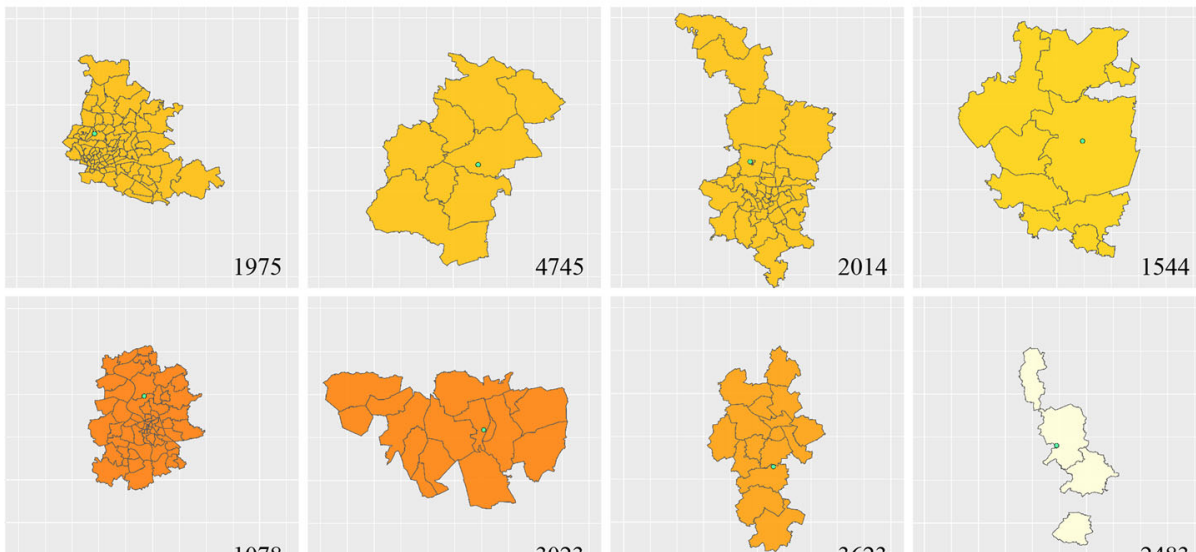

1078

3023

3623
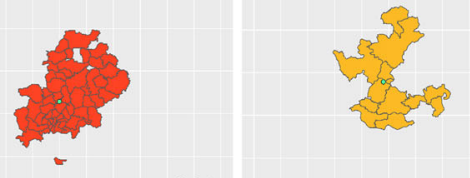

4928
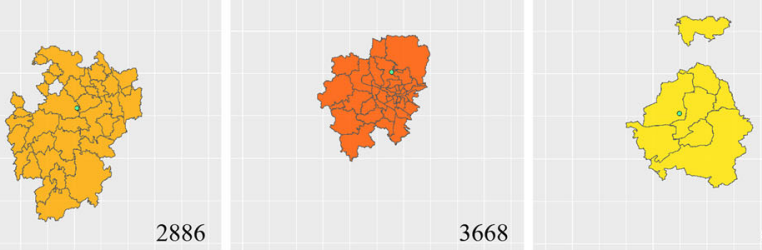

3668

6305

Fig. 2 Mean daily temperature for different weather stations across Germany. Depicted are weather stations (green) and the borders of the corresponding postal areas across Germany; the gridlines indicate degree minutes in latitude/longitude; the background coloring indicates the mean daily temperature (Source: DWD)

varied considerably across weather stations, ranging between 4.3 and $24.0^{\circ} \mathrm{C}$ (between $17.2{ }^{\circ} \mathrm{C}$ at station 2483 and $23.4{ }^{\circ} \mathrm{C}$ at station 1424 for the example in Fig. 2), indicating greatly different local weather experiences for respondents from different neighborhoods.

To measure respondents' climate change perceptions and attitudes, we relied on three different items recording whether climate change is considered the most important problem facing the country, whether fighting climate change should be prioritized over economic growth, and whether cars with combustion engines should be allowed to be registered after 2030 (see Appendix 5 for question wording and coding). The first item is binary and captures 
Table 1 Dependent variables

\begin{tabular}{lllllll}
\hline & Mean & Mdn & SD & Min & Max & Waves \\
\hline Problem awareness & 0.03 & 0 & 0.17 & 0 & 1 & $1-12$ \\
Policy priority & 0.64 & 0.5 & 0.26 & 0 & 1 & $1,2,4,7,8,10-12$ \\
Solution preference & 0.40 & 0 & 0.33 & 0 & 1 & $4-8,11-12$ \\
\hline
\end{tabular}

respondents' general awareness of climate change as a problem, ${ }^{5}$ whereas the second item queries respondents' priorities when faced with conflicting policy aims on a 7-point scale. The third item records respondents' support for a specific measure to fight climate change on a 5point scale and may thus be contested among respondents who support climate protection measures in general. Hence, the three measures capture different levels of commitment to fighting climate change, from problem awareness to specific policy measures. Unfortunately, only the last wave of the panel included an item asking respondents about the existence of climate change, preventing its inclusion in the analysis. However, given that over $90 \%$ of Germans accept the existence of climate change (ESS Round 8 2016), the greater variation in the three available items allows us to capture more nuanced shifts in respondents' problem awareness, priorities, and policy preferences.

Table 1 displays descriptive statistics for each item and details the waves in which they were queried. Since the survey waves were timed to match the election cycle and the items were not included in every wave, the intervals between interviews vary considerably from a week to 6 months, raising the question how people processed the experienced local weather conditions. Irrespective of preferences for on-line or memory-based models of information processing (Kim and Garrett 2012; Lodge et al. 1995), longer intervals could make identification more difficult because respondents likely perceived more potentially relevant stimuli between interviews. We can thus leverage the different interval lengths to gauge the longevity of attitude changes associated with local weather conditions.

Whereas most previous studies working with fine-grained weather data relied on crosssectional surveys and thus examined inter-individual differences between the climate change beliefs of respondents who experienced different weather conditions, we used panel data to explore intra-individual differences over time. Specifically, the panel data allowed us to test whether unusual variations in local weather between two survey waves elicited changes in respondents' climate change attitudes relative to their previous positions. While cross-sectional designs can only control for a finite number of individual- and regional-level confounders, the panel design minimizes unobserved heterogeneity (cf. Howe et al. 2019). To confound the results, omitted variables would need to emerge between survey waves, eliminating the influence of long-term and asynchronous factors. In combination with the high spatial resolution of the data, confounding factors would additionally need to mirror the spatial distribution of the weather stations. This constellation rules out most of the factors that have been shown to influence people's climate change attitudes because their spatial distribution differs considerably from the distribution of weather stations. This includes coverage by

\footnotetext{
5 This item prompts respondents to name the one most important problem facing the country (see Appendix 5 for the precise wording), but many respondents still name more than one problem. Since any mention in response to the question is obviously salient in the respondents' minds, climate change was recorded as the most important problem even if it was mentioned alongside other problems.
} 
national, regional, and most local media, as well as election campaign messages that may be of special concern for a survey instrument timed to represent the election cycle.

Although the panel design increases our confidence that we capture the impact of local weather, we cannot preclude the possibility that local weather conditions affect respondents' climate change attitudes in conjunction with other factors. For instance, people may experience high temperatures but only perceive this experience as unusual and associate it with climate change because the media tell them that climate change has brought the second-hottest summer in two centuries. In this case, the personal experience and the media report would jointly change people's climate policy preferences. We thus argue only that the personal experience played an integral part in the change, not that it is solely responsible. Similarly, people may experience unusual variations in local weather vicariously through a personal conversation or a local radio report rather than personally. Importantly, vicarious experiences will only be captured if they relate to local weather conditions in the respondents' immediate environment that could have been personally experienced; we thus remain agnostic about this question.

To analyze the influence of unusual variations in local weather, we first calculated changes in respondents' climate change positions to obtain dynamic dependent variables. Accordingly, problem_c indicates whether a respondent who did not name climate change as the most important problem in the previous survey wave named it in the current wave, whereas priority_c and solution_c capture changes in respondents' positions on these items. The weather variables were recoded to reflect the number of days, or months in the case of drought, for which unusual weather events were recorded in between the previous survey wave and the day of the interview for the current survey wave. Hence, the values of these variables differ across weather stations and survey days but are identical for respondents who live near the same weather station and completed their interview on the same day.

To account for this three-level data structure, we estimated mixed-effects models with fixed effects and random intercepts for the weather station and interview date. Considering that the weather at different stations across Germany is not necessarily more similar on the same day than on different days, the random intercept for the interview date is nested within the regional cluster of weather stations. ${ }^{6}$ Since we are analyzing intra-individual changes, individual-level controls are not required.

Instead of using mixed-effects models, even sophisticated previous research has tended to rely on adding fixed effects for temporal and regional clusters to standard regression models and clustering the standard errors at the level where the weather variations occur (cf. Egan and Mullin 2012), partly because meaningful mixed-effects estimates require very large samples. However, models without random intercepts for clusters included as fixed effects effectively ignore within-level interdependencies and may thus lead to seriously downward-biased standard errors (Schmidt-Catran and Fairbrother 2016). The inclusion of random intercepts prevents this bias and can therefore be expected to result in more accurate estimations. To explore the severity of the bias for models that rely on fixed effects with clustered standard errors only, we re-ran all models with fixed effects for the weather station and interview date, clustering the standard errors at the station level.

Finally, we explored potential heterogeneous effects for people who are routinely more or less affected by local weather conditions. Unfortunately, the number of farmers in the sample

\footnotetext{
${ }^{6}$ While crossed random intercepts control for any unexpected variation and are thus generally preferable to nested random intercepts (Schmidt-Catran and Fairbrother 2016), the sample is too small to estimate meaningful crossed random intercepts for all weather stations and interview dates.
} 
was too small to obtain meaningful estimates for this heavily affected subgroup; however, older people also tend to be more immediately affected by extreme weather events. Hence, we re-ran the models capturing changes from November 2018 to November 2019 for different age groups to test whether people aged 60 and older were more likely to respond to local weather conditions than younger respondents. To assess whether local weather conditions more strongly affected people who are more locally minded, we re-ran the same models separately for respondents who indicated that they were strongly or rather strongly attached to their municipality and respondents who felt at most moderately attached. ${ }^{7}$ In addition, we explored whether respondents' level of education or gender influenced their propensity to link local weather conditions to climate change and to adjust their related attitudes (see Appendix 5 for question wording and coding).

In principle, climate change skeptics have the largest potential for changing their climaterelated attitudes in response to local weather extremes, whereas people who accept the existence of climate change likely already adjusted their attitudes and hence experience a ceiling effect. Although we suspect that motivated reasoning prevented climate change skeptics from realizing this potential, we empirically tested this assumption with data collected in November 2019, when respondents were asked whether or not they believed that the climate is changing. We re-ran the according models separately for climate change skeptics and acceptors to capture potential differences between these groups.

\section{Results}

To test whether weather conditions that either were or could have been personally experienced affect people's perceptions of climate change as a problem, their willingness to prioritize climate protection over economic growth, and their preferences regarding climate protection measures, specifically the registration of cars with combustion engines after 2030, we first estimated mixed-effects models with fixed effects and random intercepts for the weather station and interview date for all available survey waves. ${ }^{8}$ The independent variables are the indicators for absolute and relative heat, oppressiveness, absolute and relative cold, (thunder-)storms, heavy rain- and snowfall, and drought, measured between the survey wave in which the dependent variable was collected and the previous wave. We estimate the likelihood that respondents name climate change as the most important problem when it was not named in the previous wave using logistic regressions (models A.1.) and changes in respondents' policy priorities (models A.2.) and solution preferences (models A.3.) using linear regression. For the latter models, positive coefficients indicate priority shifts in favor of climate protection and not registering cars with combustion engines after 2030, respectively. To allow for easy interpretation and comparison of the results from the 18 mixed-effects models and 19 fixedeffects models with clustered standard errors, the results are depicted in specification curves, which include point estimates with $95 \%$ confidence intervals for the ten independent weather variables (listed on the left) and indicate the respective dependent variable, the modeling

\footnotetext{
${ }^{7}$ We also re-ran the models only for those respondents who felt strongly attached to their municipality, with substantively unchanged results.

${ }^{8}$ Convergence was not achieved for problem awareness in waves 3 and 8 , policy priorities in waves 7 and 8 , and solution preferences in wave 8 (wave 8 was the post-election wave, collected only days after the previous wave).
} 
Fig. 3 Impact of local weather conditions on problem awareness, policy priorities, and solution preferences. Depicted are coefficients for the ten weather indicators with $95 \%$ confidence intervals. The weather indicators are listed on the left and ordered by model specification; i.e., coefficients from the same model are depicted below each other. The legend on the bottom indicates the respective dependent variable (DV) for each column of coefficients, whether mixed-effects (models A) or fixed-effects with clustered standard errors (models B) were estimated, and whether logistic or linear regression was used (model). The data collection period is also reported (wave). Significant effects are highlighted in red

strategy, and the survey waves in which the data was collected in the bottom (Simonsohn et al. 2020).

Supporting the first hypothesis, the results displayed in Fig. 3 show that local weather conditions do not affect people's awareness of climate change as a problem, their policy priorities, or their solution preferences (see Appendix 7 for the full regression results). Only 7 out of 176 coefficients achieve statistical significance (highlighted in red), which is less than the nine coefficients that would be expected to be significant by chance alone. Moreover, the significant coefficients do not follow any pattern that would indicate a systematic short- or long-term influence of local weather conditions on either problem awareness, policy priorities, or solution preferences. Contrary to our initial expectations, there is no evidence that problem awareness is affected more than specific policy preferences, nor that weather phenomena commonly associated with climate change influence people's perceptions and attitudes more strongly. Hence, the empirical evidence does not corroborate the second or third hypothesis. The coefficients do not pass conventional levels of statistical significance across all waves, indicating that local weather conditions had neither ephemeral nor lasting effects. In short, even the unusual and relatively extreme local weather conditions observed during the data collection period did not influence the climate-related attitudes of the population at large.

In a second step, we aimed to determine whether model specification matters for the results and substantive conclusions. To this end, we re-estimated all models ${ }^{9}$ using only the fixed effects and standard errors clustered at the station level to assess how this common model specification affects the results. Comparing the coefficients of the fixed-effects models (models B) shown on the right-hand side of Fig. 3 with the mixed-effects models on the left (models A), we see that 52 out of 186 coefficients are statistically significant, some of them indicating rather large effects. This equals roughly $28 \%$ of all coefficients, which is seven times as many as with the mixed-effects models and considerably more than 5\%, suggesting that the standard errors are severely underestimated in models without random intercepts.

These results demonstrate that studies which fail to take within-level interdependencies into account will routinely overestimate the influence of weather phenomena, especially when using cross-sectional designs with a single dependent variable. In the large time series at hand, it is easy to see that the significant coefficients do not follow any systematic pattern. However, the number of significant coefficients suggests that every third or fourth cross-sectional estimation may return a false positive. In the absence of additional estimates, this effect will likely be interpreted at face value, resulting in misleading conclusions about the impact of local weather phenomena on people's climate change beliefs and related attitudes.

Although local weather conditions do not influence people's climate change beliefs and related attitudes in the population at large, they may still be important predictors for the beliefs and attitudes of people who, for whatever reason, are more attentive to their local weather. One

\footnotetext{
${ }^{9}$ The number of coefficients differs because, unlike the mixed-effects models, the fixed-effects models failed to converge for problem awareness in wave 12 but converged for respondents' policy priorities and solution preferences in wave 8 .
} 


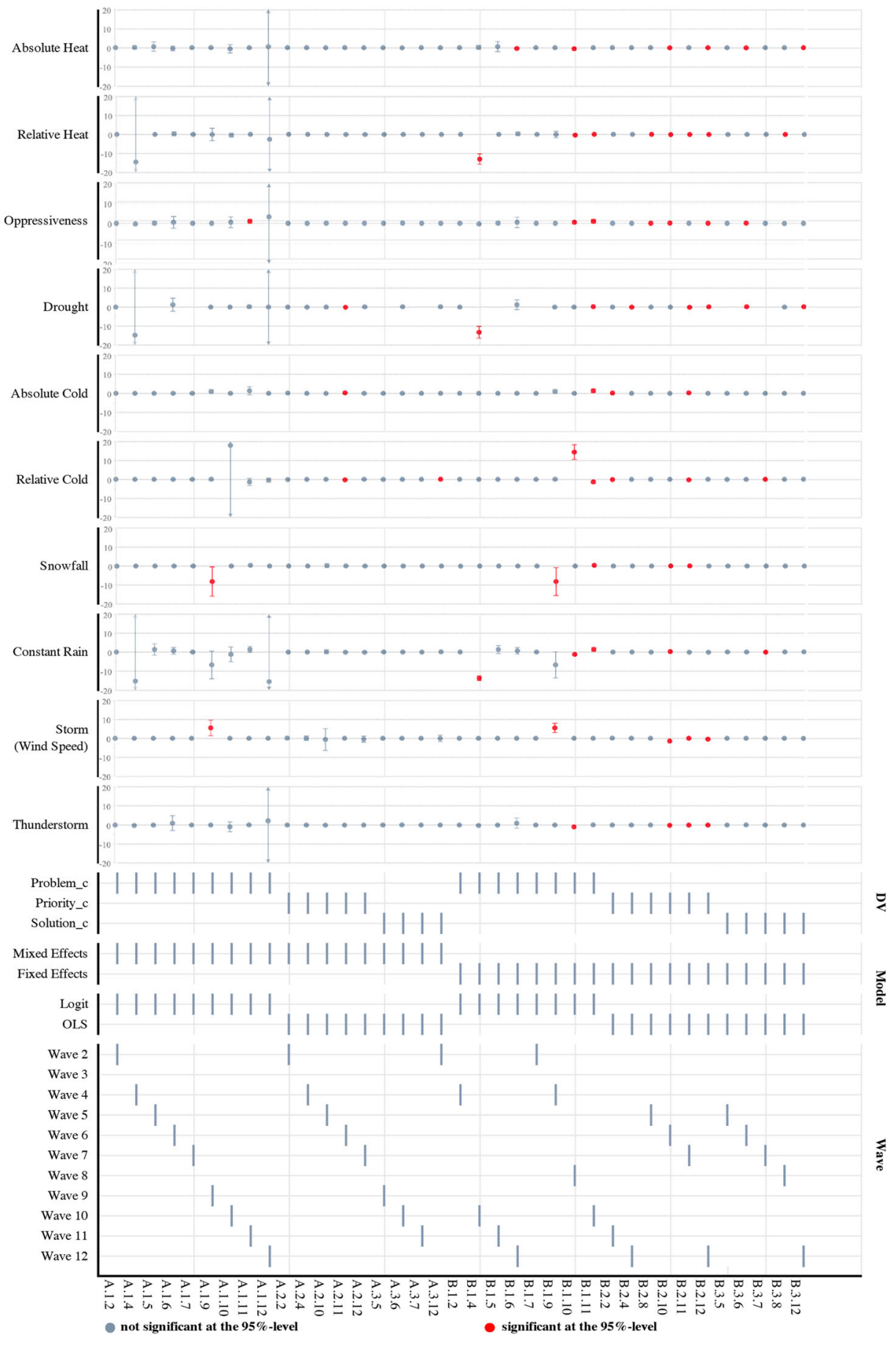


segment of the population whose daily life is routinely more affected by local weather conditions and for whom the local weather could thus have a more pronounced impact are older people. This is not the case, as the models depicted on the left hand in Fig. 4 show no systematic pattern of effects, even for this likely case (see Appendix 8 for the full regression results). Another group whose climate-related attitudes may be more strongly affected by local

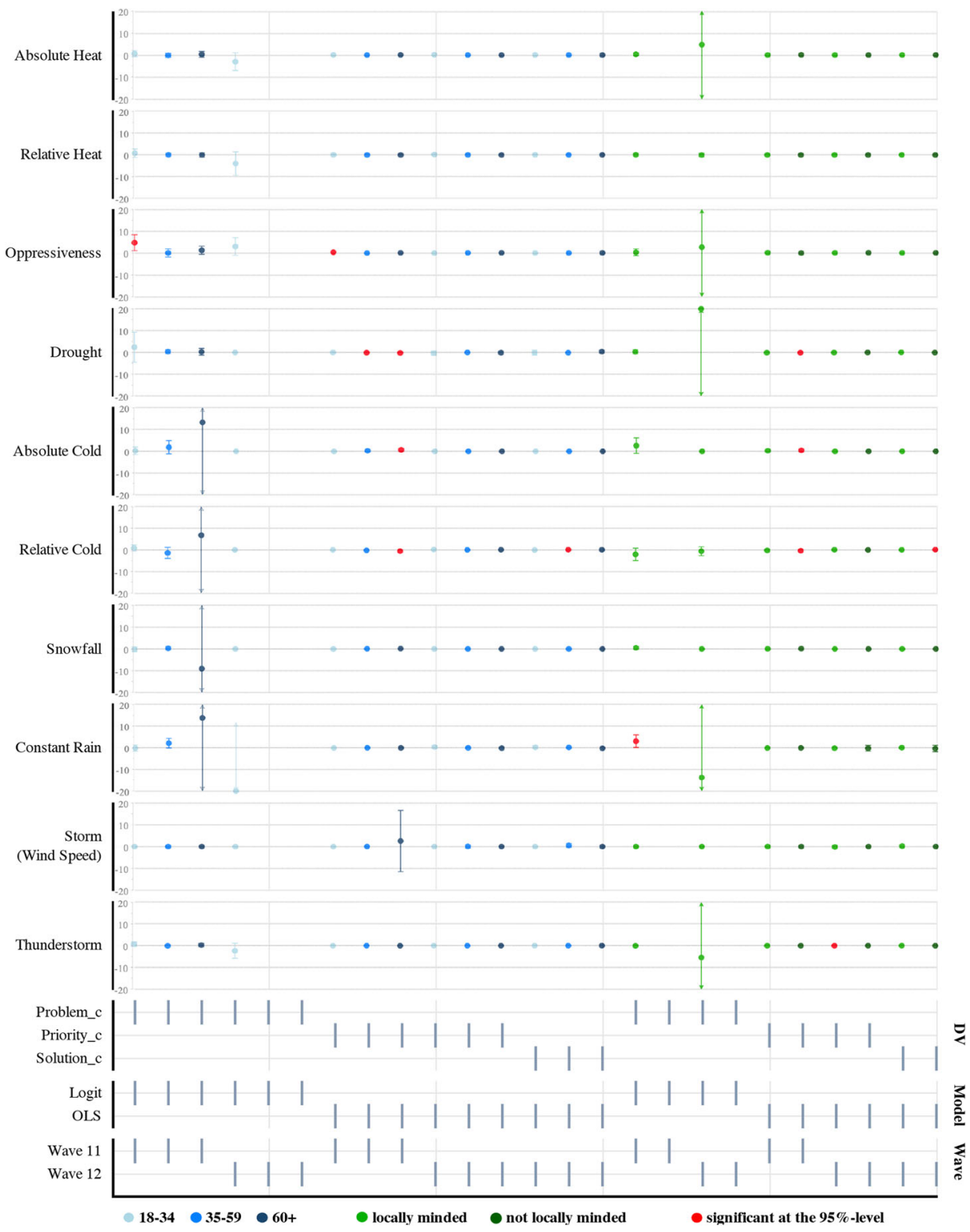

Fig. 4 Impact of local weather conditions on problem awareness, policy priorities, and solution preferences by age group (blue markers) and municipal attachment (green markers) between Nov. 2018 and Nov. 2019. Depicted are coefficients for the ten weather indicators with $95 \%$ confidence intervals from mixed-effects models only. See the caption of Fig. 3 for further interpretative guidance 
weather conditions are people who are more focused on their local surroundings, but the models depicted on the right hand in Fig. 4 also show no evidence of meaningful variation. Hence, neither hypothesis $4 \mathrm{a}$ nor $4 \mathrm{~b}$ is empirically supported by the results. Similarly, respondents' gender and level of education do not seem to play a role (see Appendix 9).

In November 2019, respondents were also asked whether or not they believed that the climate is changing, enabling us to explore the impact of existing predispositions. To reiterate, climate change skeptics have the largest potential for changing their climate-related attitudes, but motivated reasoning likely prevents them from associating variations in local weather with climate change. On the other hand, people who accept the existence of climate change likely already have corresponding priorities and preferences, leaving only those who believe that climate change exists, but who had not previously considered climate change to be a personal risk, with potential for change. In line with hypothesis 1 and contrary to hypothesis 5 , the subgroup analyses show no differences between climate change skeptics and acceptors, as neither group's problem awareness, policy priorities, or solution preferences are affected by their local weather (see Appendix 10 for the regression results).

\section{Conclusion}

A growing literature implies that the increasingly tangible consequences of climate change may heighten people's personal risk perception and their willingness to support climate protection policies. While there is evidence that experiencing unusual variations in local weather conditions or extreme weather events increases the likelihood of accepting the existence of climate change, the impact of personal experiences on attitudes that are more closely related to political action has received less empirical scrutiny (for an exception, see Rudman et al. 2013). We examined the influence of unusual and extreme local weather conditions on people's awareness of climate change as a (political) problem, their willingness to prioritize climate protection over economic growth, and their position on banning combustion engines from 2030 onwards. The results from panel survey data collected in Germany show that the indicators for ten different local weather phenomena associated with climate change were neither related to respondents' positions on concrete climate protection measures nor to their policy priorities. Experiencing unusual weather conditions did not even raise the likelihood that respondents perceived climate change as one of the most important problems facing the country, and this pattern held across several subgroups theorized to be particularly affected by local weather conditions. In short, personal experiences with unusual or extreme weather may affect people's belief in the existence of climate change, but this belief does not seem to find expression in their policy positions.

This finding suggests some caution against the role of personal experiences in shaping people's views of climate change and related policies. Given similar findings on other, for instance economic (e.g., Duch and Stevenson 2008), conditions and considering the large number of assumptions underlying the linkage between personal experiences with unusual or extreme weather events and people's climate-related attitudes, this pattern is not entirely surprising. It is beyond the scope of this paper to detail which factors contributed to the unresponsiveness of people's problem awareness and policy preferences to local weather extremes. Thus, questions regarding, for instance, whether political predispositions biased weather perceptions and their processing, or whether people were unable or unwilling to connect personal experiences to their political views, remain unclear. Likewise, our analysis 
does not preclude the possibility that, in line with the primacy of sociotropic perceptions, weather phenomena at a different scale such as the national level affected citizens' views and attitudes. Future research should therefore take a closer look at such alternative effects and the mechanisms preventing personal weather phenomena from strongly affecting citizens' attitudes towards climate change and related policies.

Like any empirical research, this analysis suffers from methodological limitations. Although the intervals between the survey waves ranged between several days and up to 6 months, the shorter intervals were clustered around the federal election in September 2017 and rather uneventful with regard to the weather. In consequence, our research design may have failed to capture short-term effects of local weather events. While such ephemeral effects would be of interest to better understand the psychological mechanisms underlying risk assessments, they would also be unlikely to affect people's policy choices in a sustained manner and hence largely irrelevant for explaining climate-friendly policy outcomes.

Moreover, our results are bound to Germany from 2016 to 2019. The personal experience hypothesis may have fared better in a period or region with more extreme weather events of longer duration with more tangible personal consequences. Likewise, studying these effects in an earlier period when climate change and related policies were rather novel and less politicized phenomena may have resulted in a different picture. Although we included a range of dependent variables to ensure that the results are not specific to one indicator, there may be climate protection policies that are perceived as more closely linked to local weather and, hence, potentially more susceptible to unusual variations in local weather conditions than our dependent variables. We thus suggest additional research using similar research designs to explore the generalizability of these findings.

Notwithstanding these limitations, our analysis suggests some caution against the idea that personal experiences with local weather phenomena easily translate into specific perceptions of climate change and attitudes towards related policies. Political attitudes and public opinions do not simply reflect personal experience, but are formed in complicated processes entailing numerous other factors. In some cases, such a disconnect may indicate that people care for the nation or the globe, instead of their personal conditions. In others that people fail to respond strongly to clear indications of problems. Building on the idea that public policy should be somewhat in accordance with public opinion, the not overly strong link between personal experiences and political attitudes adds another complication to public policy-making under democratic governance.

Supplementary Information The online version contains supplementary material available at https://doi.org/ 10.1007/s10584-021-03176-z.

Acknowledgements We wish to thank the DWD team for their support in obtaining and understanding the analyzed weather data and Marius Albrecht for excellent research assistance.

Code availability The Stata code for the analyses is available at https://doi.org/10.17605/OSF.IO/8B62S. The Stata and $\mathrm{R}$ codes used to construct the dataset are available on request from the corresponding author. 
Author contribution L. Gärtner and H. Schoen collaboratively conceived this paper. L. Gärtner wrote the initial draft, designed and performed the analyses, and visualized and interpreted the corresponding results. $\mathrm{H}$. Schoen critically revised and edited previous versions of the manuscript. All authors read and approved the final manuscript.

Funding Open Access funding enabled and organized by Projekt DEAL. This work was supported by the German Research Foundation (Grant number SCHO 1358/4-3).

Data availability The data that support the findings of this study are available at https://doi.org/10.17605/OSF. IO/8B62S. In compliance with the General Data Protection Regulations, the provided data does not include the personally identifiable information on respondents' postal codes, which was used to match the individual-level and weather data. However, the raw data is available for analysis at the GESIS - Leibniz-Institut für Sozialwissenschaften Secure Data Center in Cologne.

\section{Declarations}

Ethical approval Not applicable.

Consent to participate Not applicable.

Consent to publish Not applicable.

Conflict of interest The authors declare competing interests.

Open Access This article is licensed under a Creative Commons Attribution 4.0 International License, which permits use, sharing, adaptation, distribution and reproduction in any medium or format, as long as you give appropriate credit to the original author(s) and the source, provide a link to the Creative Commons licence, and indicate if changes were made. The images or other third party material in this article are included in the article's Creative Commons licence, unless indicated otherwise in a credit line to the material. If material is not included in the article's Creative Commons licence and your intended use is not permitted by statutory regulation or exceeds the permitted use, you will need to obtain permission directly from the copyright holder. To view a copy of this licence, visit http://creativecommons.org/licenses/by/4.0/.

\section{References}

Akerlof K, Maibach EW, Fitzgerald D, Cedeno AY, Neuman A (2013) Do people "personally experience" global warming, and if so how, and does it matter? Glob Environ Chang 23(1):81-91. https://doi.org/10. 1016/j.gloenvcha.2012.07.006

Alló M, Loureiro ML (2014) The role of social norms on preferences towards climate change policies: a metaanalysis. Energy Policy 73:563-574. https://doi.org/10.1016/j.enpol.2014.04.042

Borick CP, Rabe BG (2014) Weather or not? Examining the impact of meteorological conditions on public opinion regarding global warming. WCAS 6(3):413-424. https://doi.org/10.1175/WCAS-D-13-00042.1

Brooks J, Oxley D, Vedlitz A, Zahran S, Lindsey C (2014) Abnormal daily temperature and concern about climate change across the United States. Rev Policy Res 31(3):199-217. https://doi.org/10.1111/ropr.12067

Brulle RJ, Carmichael J, Jenkins JC (2012) Shifting public opinion on climate change: an empirical assessment of factors influencing concern over climate change in the U.S., 2002-2010. Clim Chang 114(2):169-188. https://doi.org/10.1007/s10584-012-0403-y

Capstick SB, Pidgeon NF (2014) Public perception of cold weather events as evidence for and against climate change. Clim Chang 122(4):695-708. https://doi.org/10.1007/s10584-013-1003-1

Deutsche Welle (2018) After the drought, the storm: German weather chaos continues. DW. https://p.dw.com/p/ 32wS9. Last accessed on 08-04-2021

Devine-Wright P, Price J, Leviston Z (2015) My country or my planet? Exploring the influence of multiple place attachments and ideological beliefs upon climate change attitudes and opinions. Glob Environ Chang 30:6879. https://doi.org/10.1016/j.gloenvcha.2014.10.012 
Duch RM, Stevenson RT (2008) The economic vote: how political and economic institutions condition election results. Cambridge University Press

DWD (2018) Schadensrückblick des Deutschen Wetterdienstes für die letzten 12 Monate. Deutscher Wetterdienst. https://www.dwd.de/DE/presse/pressemitteilungen/DE/2018/20181213 schadensrueckblick2018 news.html

DWD Climate Data Center (CDC) (2018) Historical daily station observations (temperature, pressure, precipitation, sunshine duration, etc.) for Germany, (Version: V006)

Egan PJ, Mullin M (2012) Turning personal experience into political attitudes: the effect of local weather on Americans' perceptions about global warming. J Polit 74(3):796-809. https://doi.org/10.1017/ S0022381612000448

ESS Round 8 (2016) European Social Survey Round 8 Data. Data file edition 2.2. NSD - Norwegian Centre for Research Data, Norway - Data Archive and Distributor of ESS Data for ESS ERIC. 10.21338/NSD-ESS82016

Eurobarometer (2019) Report: climate change (no. 490; special Eurobarometer). European Commission. https:// ec.europa.eu/clima/sites/clima/files/support/docs/report 2019 en.pdf. Last accessed on 08-04-2021

Evans G, Pickup M (2010) Reversing the causal arrow: the political conditioning of economic perceptions in the 2000-2004 U.S. presidential election cycle. J Polit 72(4):1236-1251. https://doi.org/10.1017/ S0022381610000654

Fazio RH, Zanna MP (1981) Direct experience and attitude-behavior consistency. In: Berkowitz L (ed) Advances in experimental social psychology, 14th edn. Academic Press, pp 161-202

Field CB, Barros V, Stocker TF, Dahe Q, Dokken DJ, Ebi KL, Mastrandrea MD, Mach KJ, Plattner G-K, Allen SK, Tignor M, Midgley PM (eds) (2012) Managing the risks of extreme events and disasters to advance climate change adaptation: a special report of working groups I and II of the intergovernmental panel on climate change. Cambridge University Press, Cambridge

Fielding KS, Hornsey MJ (2016) A social identity analysis of climate change and environmental attitudes and behaviors: insights and opportunities. Front Psychol 7:121. https://doi.org/10.3389/fpsyg.2016.00121

Filiberto D, Wethington E, Pillemer K, Wells NM, Wysocki M, Parise JT (2009) Older people and climate change. ASA Generations 33(4):19-25. JSTOR. https://doi.org/10.2307/26555689

Flynn C, Yamasumi E, Fisher S, Snow D, Grant Z, Kirby M, Browning P, Rommerskirchen M, Russell I (2021) Peoples' climate vote: results. UNDP. https:/www.undp.org/sites/g/files/zskgke326/files/publications/ UNDP-Oxford-Peoples-Climate-Vote-Results.pdf. Last accessed on 08-04-2021

Friedrich K, Kaspar F (2019) Rückblick auf das Jahr 2018 - Das bisher wärmste Jahr in Deutschland. Deutscher Wetterdienst - Abteilung Klimaüberwachung

Gilbert DT, Malone PS (1995) The correspondence bias. Psychol Bull 117(1):21-38. https://doi.org/10.1037/ 0033-2909.117.1.21

GLES (2019) GLES 2017 pre- and post-election cross section (Cumulation) (Version 3.0.1). GESIS Data Archive, Cologne. https://doi.org/10.4232/1.13236

Handelsblatt (2019) Waldbrände wüten in Mecklenburg-Vorpommern - Mehrere Ortschaften evakuiert. Handelsblatt. https:/www.handelsblatt.com/politik/deutschland/naturkatastrophe-waldbraende-wueten-inmecklenburg-vorpommern-mehrere-ortschaften-evakuiert/24514654.html?ticket=ST-3906DXJunoroobUXbO9j2ZMj-ap6. Last accessed on 08-04-2021

Hersbach H, Bell B, Berrisford P, Biavati G, Horányi A, Muñoz Sabater J, Nicolas J, Peubey C, Radu R, Rozum I, Schepers D, Simmons A, Soci C, Dee D, Thépaut J-N (2018) ERA5 hourly data on single levels from 1979 to present. Copernicus Climate Change Service (C3S) Climate Data Store (CDS). https://doi.org/10. 24381/cds.adbb2d47

Hoffarth MR, Hodson G (2016) Green on the outside, red on the inside: erceived environmentalist threat as a factor explaining political polarization of climate change. J Environ Psychol 45:40-49. https://doi.org/10. 1016/j.jenvp.2015.11.002

Hornsey MJ, Harris EA, Bain PG, Fielding KS (2016) Meta-analyses of the determinants and outcomes of belief in climate change. Nat Clim Chang 6(6):622-626. https://doi.org/10.1038/nclimate2943

Howe PD, Leiserowitz A (2013) Who remembers a hot summer or a cold winter? The asymmetric effect of beliefs about global warming on perceptions of local climate conditions in the U.S. Glob Environ Chang 23(6):1488-1500. https://doi.org/10.1016/j.gloenvcha.2013.09.014

Howe PD, Boudet H, Leiserowitz A, Maibach EW (2014) Mapping the shadow of experience of extreme weather events. Clim Chang 127(2):381-389. https://doi.org/10.1007/s10584-014-1253-6

Howe PD, Marlon JR, Mildenberger M, Shield BS (2019) How will climate change shape climate opinion? Environ Res Lett 14(11):113001. https://doi.org/10.1088/1748-9326/ab466a

Imbery F, Bissolli P, Daßler J, Haeseler S (2019) Neuer Rekord der mittleren Junitemperatur für Deutschland und intensive Hitzewelle in Europa. Deutscher Wetterdienst - Abteilung Klimaüberwachung. https://www.dwd. 
de/DE/leistungen/besondereereignisse/temperatur/20190703_bericht_juni2019.pdf?_blob= publicationFile\&v=1. Last accessed on 08-04-2021

Inglehart R (1970) Public opinion and regional integration. Int Organ 24(4):764-795. Cambridge Core. https:// doi.org/10.1017/S0020818300017525

Jones EE, Harris VA (1967) The attribution of attitudes. J Exp Soc Psychol 3(1):1-24. https://doi.org/10.1016/ 0022-1031(67)90034-0

Kahneman D, Slovic P, Tversky A (eds) (1982) Judgement under uncertainty: heuristics and biases. Cambridge University Press. https://oi.org/10.1017/CBO9780511809477

Keller C, Siegrist M, Gutscher H (2006) The role of the affect and availability heuristics in risk communication. Risk Anal 26(3):631-639. https://doi.org/10.1111/j.1539-6924.2006.00773.x

Kim YM, Garrett K (2012) On-line and memory-based: revisiting the relationship between candidate evaluation processing models. Polit Behav 34(2):345-368. https://doi.org/10.1007/s11109-011-9158-9

Konisky DM, Hughes L, Kaylor CH (2016) Extreme weather events and climate change concern. Clim Chang 134(4):533-547. https://doi.org/10.1007/s10584-015-1555-3

Krosnick JA, Holbrook AL, Lowe L, Visser PS (2006) The origins and consequences of democratic citizens' policy agendas: a study of popular concern about global warming. Clim Chang 77(1):7-43. https://doi.org/ 10.1007/s10584-006-9068-8

Kuchler T, Zafar B (2019) Personal experiences and expectations about aggregate outcomes. J Financ 74(5): 2491-2542. https://doi.org/10.1111/jofi.12819

Kunda Z (1990) The case for motivated reasoning. Psychol Bull 108(3):480-498. https://doi.org/10.1037/00332909.108.3.480

Lang C (2014) Do weather fluctuations cause people to seek information about climate change? Clim Chang 125(3):291-303. https://doi.org/10.1007/s10584-014-1180-6

Li Y, Johnson EJ, Zaval L (2011) Local warming: daily temperature change influences belief in global warming. Psychol Sci 22(4):454-459. https://doi.org/10.1177/0956797611400913

Lodge M, Taber CS (2013) The rationalizing voter. Cambridge University Press, Cambridge Core. https://doi. org/10.1017/CBO9781139032490

Lodge M, Steenbergen MR, Brau S (1995) The responsive voter: campaign information and the dynamics of candidate evaluation. Am Polit Sci Rev 89(2):309-326. JSTOR. https://doi.org/10.2307/2082427

Lord CG, Ross L, Lepper MR (1979) Biased assimilation and attitude polarization: the effects of prior theories on subsequently considered evidence. J Pers Soc Psychol 37(11):2098-2109

Lujala P, Lein H, Rød JK (2015) Climate change, natural hazards, and risk perception: the role of proximity and personal experience. Local Environ 20(4):489-509. https://doi.org/10.1080/13549839.2014.887666

Marquart-Pyatt ST, McCright AM, Dietz T, Dunlap RE (2014) Politics eclipses climate extremes for climate change perceptions. Glob Environ Chang 29:246-257. https://doi.org/10.1016/j.gloenvcha.2014.10.004

McCright AM, Dunlap RE (2011) The politicization of climate change and polarization in the American public's views of global warming, 2001-2010. Sociol Q 52(2):155-194. https://doi.org/10.1111/j.1533-8525.2011. 01198.x

Meinert T, Becker A, Bissolli P, Daßler J, Breidenbach JN, Ziese M (2019) Ursachen und Folgen der Trockenheit in Deutschland und Europa ab Juni 2019. Deutscher Wetterdienst - Abteilung Klimaüberwachung. https:/www.dwd.de/DE/leistungen/besondereereignisse/duerre/20190712 trockenheit juni juli 2019.pdf? blob=publicationFile \&v=1. Last accessed on 08-04-2021

Myers TA, Maibach EW, Roser-Renouf C, Akerlof K, Leiserowitz AA (2013) The relationship between personal experience and belief in the reality of global warming. Nat Clim Chang 3(4):343-347. https://doi.org/10. 1038/nclimate 1754

Nicolai B (2018) In Norddeutschland herrscht die größte Dürre seit 15 Jahren. Welt. https://www.welt.de/ wirtschaft/article177217410/Wasserversorgung-In-Deutschland-herrscht-die-groesste-Duerre-seit-15Jahren.html. Last accessed on 08-04-2021

Palm R, Lewis GB, Feng B (2017) What causes people to change their opinion about climate change? Ann Am Assoc Geogr 107(4):883-896. https://doi.org/10.1080/24694452.2016.1270193

Peel MC, Finlayson BL, McMahon TA (2007) Updated world map of the Köppen-Geiger climate classification. Hydrol Earth Syst Sci 11(5):1633-1644. https://doi.org/10.5194/hess-11-1633-2007

Poortinga W, Fisher S, Böhm G, Steg L, Whitmarsh L, Ogunbode C (2018) European attitudes to climate change and energy: topline results from round 8 of the European social Survey (no. 9; ESS topline results). European Social Survey ERIC

Reser JP, Bradley GL, Glendon AI, Ellul MC, Callaghan R (2012) Public risk perceptions, understandings, and responses to climate change and natural disasters in Australia and Great Britain. National Climate Change Adaptation Research Facility, Gold Cost, Australia

Reser JP, Bradley GL, Ellul MC (2014) Encountering climate change: 'seeing' is more than 'believing.' WIREs Climate Change, 5(4), 521-537. https://doi.org/10.1002/wcc.286 
Ripberger JT, Jenkins-Smith HC, Silva CL, Carlson DE, Gupta K, Carlson N, Dunlap RE (2017) Bayesian versus politically motivated reasoning in human perception of climate anomalies. Environ Res Lett 12(11): 114004. https://doi.org/10.1088/1748-9326/aa8cfc

Ross L (1977) The intuitive psychologist and his shortcomings: distortions in the attribution process. In: Berkowitz L (ed) Advances in experimental social psychology, vol 10. Academic Press, pp 173-220. https://doi.org/10.1016/S0065-2601(08)60357-3

Roßteutscher S, Schmitt-Beck R, Schoen H, Weßels B, Wolf C, Preißinger M, Kratz A, Wuttke A, Gärtner L (2018) Short-term campaign panel (GLES 2017) (version 6.0.0). GESIS data archive, Cologne. https://doi. org/10.4232/1.13150

Rudman LA, McLean MC, Bunzl M (2013) When truth is personally inconvenient, attitudes change: the impact of extreme weather on implicit support for green politicians and explicit climate-change beliefs. Psychol Sci 24(11):2290-2296. https://doi.org/10.1177/0956797613492775

Rueter G (2019) Germany among top three countries suffering most from extreme weather events. DW. https://p. dw.com/p/3UD5A. Last accessed on 08-04-2021

Schmidt-Catran AW, Fairbrother M (2016) The random effects in multilevel models: getting them wrong and getting them right. Eur Sociol Rev 32(1):23-38. https://doi.org/10.1093/esr/jcv090

Schwirplies C (2018) Citizens' acceptance of climate change adaptation and mitigation: a survey in China, Germany, and the U.S. Ecol Econ 145:308-322. https://doi.org/10.1016/j.ecolecon.2017.11.003

Shao W, Keim BD, Garand JC, Hamilton LC (2014) Weather, climate, and the economy: explaining risk perceptions of global warming, 2001-10. WCAS 6(1):119-134. https://doi.org/10.1175/WCAS-D-1300029.1

Simonsohn U, Simmons JP, Nelson LD (2020) Specification curve analysis. Nat Hum Behav 4(11):1208-1214. https://doi.org/10.1038/s41562-020-0912-z

Spence A, Poortinga W, Butler C, Pidgeon NF (2011) Perceptions of climate change and willingness to save energy related to flood experience. Nat Clim Chang 1(1):46-49. https://doi.org/10.1038/nclimate1059

Taylor A, de Bruin WB, Dessai S (2014) Climate change beliefs and perceptions of weather-related changes in the United Kingdom. Risk Anal 34(11):1995-2004. https://doi.org/10.1111/risa.12234

Tvinnereim E, Fløttum K, Gjerstad Ø, Johannesson MP, Nordø ÅD (2017) Citizens’ preferences for tackling climate change. Quantitative and qualitative analyses of their freely formulated solutions. Glob Environ Chang 46:34 41. https://doi.org/10.1016/j.gloenvcha.2017.06.005

van der Linden S (2014) On the relationship between personal experience, affect and risk perception: the case of climate change. Eur J Soc Psychol 44(5):430-440. https://doi.org/10.1002/ejsp.2008

van der Linden S (2015) The social-psychological determinants of climate change risk perceptions: towards a comprehensive model. J Environ Psychol 41:112-124. https://doi.org/10.1016/j.jenvp.2014.11.012

WAZ (2019) »Dieser Winter war erheblich zu mild«. WAZ. https://interaktiv.waz.de/winter-vergleichdeutschland/. Last accessed on 08-04-2021

Weber EU (2006) Experience-based and description-based perceptions of long-term risk: why global warming does not scare us (yet). Clim Chang 77(1):103-120. https://doi.org/10.1007/s10584-006-9060-3

Weber EU (2010) What shapes perceptions of climate change? Wiley Interdiscip Rev Clim Change 1(3):332342. https://doi.org/10.1002/wcc.41

Whitmarsh L (2008) Are flood victims more concerned about climate change than other people? The role of direct experience in risk perception and behavioural response. Journal of Risk Research 11(3):351-374. https://doi.org/10.1080/13669870701552235

Zeit Online (2018) Drei Dörfer wegen Waldbrand evakuiert. Zeit Online. https://www.zeit.de/gesellschaft/ zeitgeschehen/2018-08/brandenburg-waldbrand-evakuierung-treuenbrietzen?utm_referrer=https $\% 3 \mathrm{~A} \% 2 \mathrm{~F} \%$ 2Fwww.google.com\%2F. Last accessed on 08-04-2021

Ziegler A (2017) Political orientation, environmental values, and climate change beliefs and attitudes: an empirical cross country analysis. Energy Econ 63:144-153. https://doi.org/10.1016/j.eneco.2017.01.022

Ziese M, Becker A, Finger P, Meyer-Christoffer A, Rudolf B, Schneider U (2013) GPCC Drought Index Product (GPCC_DI) at $1.0^{\circ}$. Deutscher Wetterdienst. 10.5676/DWD_GPCC/DI_M_100

Ziese M, Schneider U, Meyer-Christoffer A, Schamm K, Vido J, Finger $\overline{\mathrm{P}}$, Bissolli P, Pietzsch S, Becker A (2014) The GPCC drought index - a new, combined and gridded global drought index. Earth System Science Data 6(2):285-295. https://doi.org/10.5194/essd-6-285-2014

Publisher's note Springer Nature remains neutral with regard to jurisdictional claims in published maps and institutional affiliations. 